\title{
Reseña Costa Rica y el Deporte (1873-1921). Un estudio Acerca del Origen del fútbol y la Construcción de un Deporte Nacional de Chester Urbina Gaitán ([1])
}

Recientemente apareció una nueva obra dedicada a la historia del balompié, esta vez publicada por la editorial de la Universidad de Nacional. Esta obra lleva como banderas el desarrollar nuevos campos de trabajo, entre ellos, la historia social del fútbol, la sociabilidad y la historia cultural. ([2]) De este modo, el licenciado Chester Urbina pretende renovar las investigaciones del deporte introduciendo nuevas variables de análisis como son los procesos de socialización, la expansión de la denominada cultura de masas y la interacción cultural entre diversos grupos sociales, todo ello visto en el periodo de dominio liberal (1873-1921). En consecuencia, el autor procura introducir al lector en problemas recién desarrolladas por la historia política y la historia social a través del entretenido mundo del deporte. ([3]) Fruto de este esfuerzo, Urbina Gaitán desmitifica la actividad deportiva como un simple entretenimiento enmarcándolo en los complicados juegos de poder del nacionalismo oficialista, las campañas morigeradoras de los sectores dominantes y el control social que se imponía en el periodo de estudio.

Formalmente, el libro “Costa Rica y el Deporte (1873-1921). Un estudio Acerca del Origen del fútbol y la Construcción de un Deporte Nacional” se divide en cinco capítulos. En el primero de ellos el autor buscó contextualizar el nacimiento del balompié dentro de un amplio crisol de actividades deportivas que trataba de promover la clase dominante. De este modo, Urbina Gaitán pretende insinuarle al lector las diversas posibilidades que existieron en nuestro país para formar un deporte nacional. Esta inquietud es válida. La lectura nos deja la duda porque el béisbol, el baloncesto, el boxeo, la pelota vasca, el tenis o el golf no fueron los deportes predilectos del costarricense como si lo llegaron a ser en otros países cercanos al nuestro.

En el segundo capítulo se aborda el origen social del balompié en Costa Rica entre 1898 y 1904 . El autor se encarga de demostrar como este deporte, luego de origen elitesco, fue apoyado decididamente por la prensa escrita, la Iglesia y el Estado. El soporte otorgado por esas respetables fuerzas sociales fue continuado por las mismas organizaciones obreras que ya en esa época se expandían en todas las “urbes” del Valle Central.

Los capítulos III y IV tienden enfatizar en el papel de la Iglesia y el Estado en la expansión del balompié. Unos para reforzar sus procesos evangelizadores y de socialización; mientras otros procuraban fomentar el clientelismo político, la secularización de la sociedad y la formulación de una identidad nacional como comunidad imaginada.

El último capítulo analiza la apropiación masiva del balompié dentro de los sectores populares y su amplia aceptación en todas las comunidades fueran estas rurales o urbanas entre 1905 y 1921.

Al libro, en general, se le pueden rescatar diversos aspectos. Entre ellos podemos mencionar los siguientes

- $\quad$ Primero que todo, hay que señalar que una de las aportaciones del trabajo es su rica revisión hemerográfica, en especial el minucioso escrutinio del material periodístico de la época que le permite al autor rescatar la mayoría de los datos que sustentan su investigación.

- $\quad$ El trabajo es una continuación de su tesis de licenciatura y de la exploración de otras áreas de la sociabilidad costarricense. ([4])

- $\quad$ El trabajo aporta un escenario sociocultural amplio donde se gestó el balompié. Por una parte, el autor demuestra como esta práctica coexistió con diversas disciplinas deportivas. Por otro lado, Urbina Gaitán indica como esta actividad fue originalmente practicado por la clase dominante y luego fue asumido por los sectores populares. En ambos casos se alude a complejos procesos de cambio cultural en nuestro medio.

- Otra contribución del trabajo es situar las prácticas deportivas en la construcción de una estructura económica capitalista, la consolidación del Estado Nacional, la migración cultural, el crecimiento urbano y el fortalecimiento de la higiene social y la eugenesia. 
- $\quad$ En ese sentido Urbina Gaitán forma parte de un grupo de historiadores deseosos de renovar y ampliar los campos de estudio de la disciplina histórica. Intención que se ha realizado en otras latitudes y que incluso divulgan sus hallazgos en los diferentes sitios de internet. ([5])

- Un aporte digno de señalar es la intención del autor de establecer el problema de la apropiación diferenciada de los productos culturales. De este modo, rescata los diversos significados sociales que tuvo el balompié entre los distintos grupos sociales.

- Asimismo, los datos brindados por el autor permiten observar como las diversas prácticas del control social y la denominada civilización de los sectores populares fueron múltiples y muchas veces mediatizadas por los llamados grupos subalternos. En consecuencia, es posible analizar cómo en el desarrollo de las prácticas sociales existió un conflicto social y cultural, a veces latente y en otras ocasiones en forma patente entre las diferentes clases sociales.

- $\quad$ Finalmente, el trabajo también señala el problema del ocio en las sociedades rurales como la costarricense. Aquí llega y plantea problemas sumamente polémicos y que son dignos de ser recogidos por la historia cultural y social.

A pesar de la contribución que nos ofrece Urbina Gaitán en su libro debemos indicar algunos aspectos importantes que deben ser debatidos en futuros trabajos. Esto con la idea de poder efectivamente renovar las investigaciones del deporte introduciendo no sólo novedosas variables de análisis sino también nuevos problemas, ya sea durante el denominado periodo liberal o en otros lapsos como pueden ser el llamado período del estado benefactor o en el angustioso mundo del neoliberalismo.

En el primer capítulo el lector resiente la falta de contextualización socio económica del país y sus grandes contrastes regionales. Tal situación permitiría comprender las grandes diferencias de la adopción del deporte. Acaso el balompié como deporte nacional se asentó inmediatamente en todo el territorio nacional. O por el contrario, como las mismas evidencias lo demuestran, hubo regiones como la Atlántica donde el béisbol y el baloncesto tuvieron un peso más trascendental por muchos años. En el caso de este espacio la popularización del fútbol se comenzó a sementar en la mayoría de la Provincia de Limón en las décadas posteriores a 1950. Por otra parte, la fuerza social que impuso ese deporte fueron las compañías bananeras y no la Iglesia y el Estado como en otros sitios del país. Asimismo, cabe preguntarse si la United Fruit Company trató de segmentar las actividades deportivas por criterios étnicos para canalizar la conflictividad obrera entre estos y no contra la misma empresa, tal y como lo hacía con los burdeles que ella misma fomentaba. ([6])

Otro tanto uno podría preguntarse para gran parte del Pacífico Central y Norte donde todavía hoy en día la monta de toros son actividades predilectas de la población. Asimismo, queda la inquietud de sí en las regiones Norte y Sur del país, en proceso de colonización, la actividad deportiva era la misma del Valle Central. Urbina Gaitán parece homogenizar a la denominada Meseta Central con todo el país. Peligro que evita ver la riqueza que el mismo desea rescatar.

En ese mismo capítulo, se nota una ausencia de los antecedentes de las prácticas deportivas y su contexto socio cultural. El autor privilegia la enumeración de las actividades atléticas promovidas por la clase dominante y el Estado. Urbina Gaitán detalla minuciosamente el año en que aparentemente se inicia la práctica deportiva, los lugares donde se ejecutaba y el proceso de institucionalización del mismo. Sin embargo, obvia la riqueza social donde estas actividades competitivas se desarrollaron. A manera de ejemplo cabe preguntarse ¿qué implicación tuvo el boxeo, la halterofilia y la lucha grecorromana en los denominados “Cocos”? Esos personajes comunales que a "cato limpio" defendían el honor y la identidad de las diferentes comunidades. ¿Qué efectos tuvo la imposición de las carreras de caballos y las nuevas formulaciones de las carreras de cintas? Es decir en aquellas prácticas como la “Carrera de San Juan”, donde a galope los diferentes jinetes trataban de “despescuezar” a un pobre gallo ubicado a cierta altura. O ¿cómo fue percibida la esgrima en una sociedad acostumbrada a dirimir ciertos conflictos a machetazos?. Asimismo, el autor no muestra como ciertas actividades como el billar fueron netamente aceptadas como deportes de hombres mientras otros se les señalaba un carácter netamente femenino y 
delicado.

La ausencia de respuestas a esas preguntas no permiten al lector llegar a la misma conclusión del autor quien afirma "A partir de 1873 -y principalmente en la década de los noventa del siglo XIXse evidencia la permanente y constante identificación del costarricense con el deporte” ([7])

En cuanto a la fecha del primer juego de balompié al autor rehuye debatir con la ya extensa bibliografía existente realizada principalmente por periodistas. Debemos confesar que la fecha del primer juego nos resulta intrascendente. No obstante, si hubiera sido interesante ver los significados sociales e imaginarios que se dan en torno a ese supuesto primer partido. Así por ejemplo, el mismo autor parece confundir la práctica atlética reglamentada con la simple actividad lúdica, es decir tiende a equiparar lo que en la época se llamaba el "match" con la "mejenga”. De esta manera, a lo largo del texto Urbina Chacón señala como en algunas ocasiones el Estado y la Iglesia patrocinaban el balompié y en otras ocasiones lo censuraban. En este sentido no cabe preguntarse ¿El Estado Costarricense y la Santa Madre Iglesia en esas censuras no estaban promoviendo una manera específica de cómo debía regirse la conducta y la sociabilidad de los sectores subalternos? Si fue así que implicaciones tuvieron el sustento ideológico de esas instituciones en la cultura popular de la Costa Rica "liberal".

Finalmente, el autor, siguiendo a Norbert Elías y a Eric Dunning, sostiene que la actividad deportiva nace con el ocio y este a su vez se genera en las sociedades modernas. De este modo, Urbina afirma:

"Cuando el ocio comienza a llegar a la vida de las sociedades agrícolas -como era el caso de la Costa Rica del Siglo XIX- es porque la vida social, política, económica y cultural de esas sociedades está siendo alterada por los valores urbanos capitalistas” ([8])

Creemos que tal afirmación debe ser debatida para el ámbito nacional. Diversos trabajos de la cultura popular han demostrado que el ocio es una actividad constantemente redefinida pero siempre presente. La denominada "Antropología del Juego" ha esbozado el carácter lúdico del ser humano, señalando el componente social del juego y su historicidad. ([9]) De hecho la actividad lúdica (tanto en sus formas pautadas como las no reglamentadas) esbozada el conflicto social, el simbolismo y la creación de identidades. Aspectos que son soslayados por el autor.

Nuestros reparos lejos de desmerecer el trabajo del licenciado Chester Urbina tienden a trazar diversos caminos de diálogo en la Historia de la Sociabilidad, nueva área de trabajo que se abre paso. Invitamos a todos los amamantes de la historia y del deporte adquirir esta publicación.

[1] Urbina, Gaitán. Costa Rica y el Deporte (1873-1921). Un Estudio acerca del Origen del Fútbol y la Construcción de un Deporte Nacional. Heredia, Costa Rica. EUNA. 2001.

[2] Urbina, Gaitán. Costa Rica y el Deporte (1873-1921)... p. 18-19.

[3] Para un recuento sobre este aspecto puede verse. Taracena, Luis Pedro. Notas para un Balance. En: Revista de Historia. Heredia, Costa Rica. EUNA-EUCR. No. Especial. 1996, pp. 244-248,

[4] Gaitán, Chester. El fútbol en San José. Un Estudio Histórico Social Acerca de su Origen (18918-1921). (Memoria de Graduación para optar al grado de Licenciado en Historia, Universidad de Costa Rica. 1996.

[5] Algunos de estos trabajos son Labriola de C. Negreiros, Plínio José. Fútbol e Identidad Nacional: El Caso de la Copa de 1938. Dirección web http://www.sirc.ca/revista (el sitio ha sido cambiado a http://www.efdeportes.com/); Mascarenhas, Gilmar. Fútbol y Modernidad en Brasil. La Geografía Histórica de una Novedad. En: Lecturas: Educación Física y Deportes.Año 3, No 10. Buenos Aires. Mayo 1998. Dirección web http://www.sirc.ca/revista (el sitio ha sido cambiado a http://www.efdeportes.com/); Franzini, Fabio. Fútbol, Identidad y Ciudadanía en Brasil en los Años 30. En Lecturas: Educación Física y Deportes. Año 3, No 10. Buenos Aires. Mayo 1998. Dirección web http://www.sirc.ca/revista (el sitio ha sido cambiado a http://www.efdeportes.com/); Falco Genovez, Patrícia El Desafío de Clío: El Deporte como Objeto de Estudio de la Historia. Lecturas: Educación Física y Deportes. Año 3, № 9. Buenos Aires. Marzo 1998. Dirección web http://www.sirc.ca/revista (el sitio ha sido cambiado a http://www.efdeportes.com/); 
Belgeri, Francisco El Fútbol Visto hace 60 Años: Rupturas y Continuidades. Lecturas: Educación Física y Deportes. Año 3, No 10. Buenos Aires. Mayo 1998. Dirección web http://www.sirc.ca/revista (el sitio ha sido cambiado a http://www.efdeportes.com/); Roberto Di Giano. El Gráfico y sus Distintas Miradas Sobre el Fútbol Lecturas: Educación Física y Deportes. Año 3, No 10. Buenos Aires. Mayo 1998. Dirección web http://www.sirc.ca/revista (el sitio ha sido cambiado a http://www.efdeportes.com/); Frydenberg, Julio. Las Reglas del Juego y la Organización de la Competencia Deportiva en Buenos Aires entre 1900 Y 1915. Lecturas: Educación Física y Deportes. Año 2, № 4. Buenos Aires. Abril 1997. Dirección web http://www.sirc.ca/revista (el sitio ha sido cambiado a http://www.efdeportes.com/); Frydenberg, Julio. Nuevos Aportes en Torno a la Historia del Fútbol Argentino. Lecturas: Educación Física y Deportes, Año 1, № 1. Buenos Aires. Mayo 1996. Dirección web http://www.sirc.ca/revista (el sitio ha sido cambiado a http://www.efdeportes.com/) y Frydenberg, Julio David Los Nombres de los Clubes de Fútbol. Buenos Aires 1880-1930. Lecturas: Educación Física y Deportes, Año 1, No 2. Buenos Aires. Setiembre 1996. Dirección web http://www.sirc.ca/revista (el sitio ha sido cambiado a http://www.efdeportes.com/).

[6] Bourgois, Philippe. Banano, Etnia y Lucha Social en Costa Rica. DEI . San José, Costa Rica.. 1994

[7] Urbina, Gaitán. Costa Rica y el Deporte (1873-1921)... p.59.

[8] Urbina, Gaitán. Costa Rica y el Deporte (1873-1921)... p. 25.

[9] Véase González Antonio. Tractatus Ludoren. Una Antropología del Juego. Editorial Anthropos. Barcelona, España. 1993. 